\title{
Design and Simulation of Solar-based Induction Heating System
}

\author{
A. Mounika ${ }^{1}$ and G. Manohar ${ }^{2}$ \\ ${ }^{1}$ PG Scholar, CVR College of Engineering/EEE Department, Hyderabad, India \\ Email: aerupulamounika77@gmail.com \\ ${ }^{2}$ Assoc. Professor, CVR College of Engineering/EEE Department, Hyderabad, India \\ Email: manohar.gangikunta@gmail.com
}

\begin{abstract}
Solar energy is abundantly available energy for the generation of heat, and one the best appliances used for this purpose is Induction heaters. For the heat generation application, the combination of solar energy with the induction heat generation technique is the productive solution. Due to high efficiency and high-power density, resonant converters with soft switching are commonly utilized in domestic induction heating applications. For induction heating applications, a low profile and an improved efficiency resonant inverter design and implementation procedure are presented. Reducing conduction losses by using automotive-grade MOSFET devices against the classical IGBT-based converter. Conversion efficiency can be increased by decreasing switching losses which can be done by reducing switching times of MOSFET devices. Heating the metallic pan with circulating eddy currents induced by a highfrequency $\mathrm{AC}$ magnetic field is the principle of the induction cooker. If the load has an electrically conducting base, then the coil within the induction cooker and the load (pan/pot) acts as a transformer. The power will be transferred with high efficiency if the conducting base is ferromagnetic. An efficient control scheme incorporated in class $E$ resonance heating by using solar power is presented. The simulation analysis is done in MATLAB-SIMULINK.
\end{abstract}

Index Terms: induction heating, solar energy, class E resonant converter, MOSFET, MATLAB-SIMULINK

\section{INTRODUCTION}

Cooking is an integral part of human life. Cooking is a necessity for people all over the world. It accounts for a serious share of energy consumption in developing countries. In the rural area, Cooking is highly dependent on inefficient biomass-based cooking. The main problems include the time that is needed to collect the firewood and other biomass by the people as they will have to walk across miles to collect firewood for cooking. Besides the cooking process using biomass generates tons of smoke leading to indoor pollution. Indoor air pollution leads to health hazards and various other environmental concerns. In urban areas, Cooking is highly dependent on liquefied petroleum gas (LPG). From time to time, the urban people suffer from an energy crisis, LPG shortage. The lack of affordable and systematic supply of LPG is a big problem for urban people. The increasing cost and scarcity of cooking gas are some of the most serious problems that we are witnessing. Therefore, there is a need to switch towards clean and efficient fuel which is known as electricity [1].

Cooking using electricity is one of the foremost clean and efficient methods of cooking as compared to biomass and other methods of cooking. Nowadays Induction heating applications are quickly gaining popularity. Domestic induction heating technology has gained more importance in present days due to features such as high efficiency, safety, cleanliness, low-cost advanced power semiconductors, high performance, and scrupulous output power control, which surpasses other conventional domestic cooking techniques.

Induction Heating ( $\mathrm{IH})$ is a famous technique for producing very high temperatures in a fraction of time. In Induction heating, the cooking vessel is a part of the heat generation process. It also uses very high-frequency electricity to heat electrically conductive materials. Since it is non-contact, the heating process does not contaminate the fabric that's being heated. Induction heating is generally used in various industries for melting, hardening, and brazing. Induction cooking is an application of IH which is generally used for residential and commercial usage [2]. Induction heating is defined as the process of heating electrically ferromagnetic (conductive) materials by a process called electromagnetic induction. Induction cooking springs from the principle of magnetic induction by inducing eddy currents within the coil that gets stimulated within the ferromagnetic material to cause heating. High efficiency is achieved, when all the magnetic field created between the coil and the pan/pot is at least $80 \%$ transferred to the coil. The cooker presents fast warming energy saving with highspeed cooking with many temperature ranges. But the extensive upsurge in the price of electricity, the lack of availability of a large amount of electricity, and the load shedding problem force us to think about yet another alternative.

The continuous exhaustion of conventional energy sources and their environmental impacts have created an interest in choosing renewable energy sources such as solarphotovoltaic, solar thermal, and wind energy, biomass, and producer gas sources to power induction heating system. The main idea of integrating renewable energy sources such as solar photovoltaic, solar thermal, wind, and biomass and hybrid forms of energy with induction heating has been proposed by many researchers around the world to meet the energy demands and reduce the environmental impact. Solar energy can help the world in experiencing the dirty and short of non-renewable resources, such as coal, etc as it is a good and clean source of energy [3].

Solar energy, a naturally abundant energy resource without any negative impact on the environment has gained the attention of academia and industrial actors over the past decades for supplementing the supply of ever-increasing 
energy demand. The need for the use of solar energy for power supply is more prominent in developing countries. The utilization of solar energy mainly depends on its availability and appropriate technology. The sun radiates an enormous amount of energy.

Solar electricity is largely used for lighting applications, powering computers, the internet, etc, solar PV can be used for cooking purposes as well. Experiments done by several researchers and experts in the field of the solar sector reveal that solar cooking is possible.

An induction cooking system makes use of electricity for generating heat, in this study solar energy is used as a source of power for the induction heating. The efficient solution for the induction heating and cooking application is combining solar energy with induction heating.

\section{INDUCTION COOKING}

Induction cooker has become quite popular due to its advantages such as fast heating, high thermal efficiency, safety, compact size, and cleanliness induction cooker. Induction cooktops are safer and easier to clean by avoiding the use of hot heating elements, inflammable gases, and open flames. The reduction in thermal inertia allows their power outputs to get adjusted and controlled with great precision. Moreover, lowering of energy costs is gained with high energy efficiency and can considerably abate ambient heating to the rest of the kitchen. When compared with other cooking methods such as gas or an ordinary electric cooker the thermal efficiency of an induction cooker is significantly higher because the energy gets transmitted into the cooking pan directly with the help of a magnetic field without dissipating any heat into the surrounding environment. Energy is converted into heat first and then used to heat the cooking pan, leading to a significant amount of waste heat and low thermal efficiency with gas or ordinary electric cookers. According to Table I , only $40 \%$ of energy is used in gas, and $47 \%$ of energy is used by high-efficiency Gas(Halogen) which is used for cooking, 58\% is used by electric stoves, and with induction cooking around $90 \%$ of energy in electricity gets used for cooking[4]. The table which is shown below several efficiencies from different sources.

TABLE I.

RANGE TOP ENERGY EFFICIENCY

\begin{tabular}{|c|c|}
\hline Sources & Efficiency(\%) \\
\hline Gas & 40 \\
\hline Halogen & 47 \\
\hline Electric & 58 \\
\hline Induction & 90 \\
\hline
\end{tabular}

\section{A. Operation of Induction Cooking}

The method of heating in which the cooking vessel is a part of the heat generation process is termed as Induction heating. In an induction cooking process, a high-frequency alternating current is passed through the inductive coil. An alternating magnetic field is generated within the vicinity of the coil due to the phenomenon of electromagnetic induction. Due to the induction, eddy currents are generated in the cooking vessel, when a cooking vessel is made up of ferromagnetic material and is placed nearby. The magnitude of the eddy current is proportional to the area of the conductor, the rate of change of flux, the strength of the magnetic field around the coil, and inversely proportional to the resistivity of the ferromagnetic material. Because of Joule's heating effect, the cooking vessel inevitably has a certain resistance, it gets heated [5]. If IEDDY is the magnitude of eddy current-induced and $R_{P}$ is the effective resistance of the cooking vessel the heat generated is given by

$$
\mathrm{Q}=\mathrm{I}^{2} \text { EDDY } \mathrm{R}_{\mathrm{P}}
$$

The basic circuit of a domestic purpose induction cooker is shown in "Fig. 1". Initially, an AC supply of $50 \mathrm{~Hz}$ is applied, in an induction cooker. It is then rectified to DC and subsequently back to a high-frequency AC source by making use of a Resonant inverter. A high frequency alternating magnetic field through an induction coil is produced with these high-frequency currents. Therefore, placing a cooking pan or a utensil close to the induction coil will induce an eddy current into the pan. Heat energy will be produced on the surface of the pan because of it. According to the Joules effect, the internal resistance of the pan causes heat to be dissipated. Thus, it is the pan itself that gets heated up and not the heater that heats up and cooks the food.

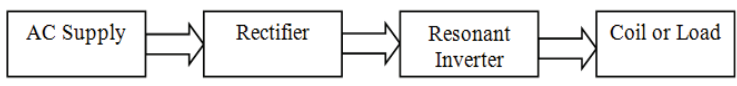

Figure 1. Induction cooking block diagram

\section{B. Advantages of Induction Cooker}

$>$ In induction heating, there is no flame employed.

$>$ There are efficient heat generation and heat transfer. (LPG-35\% efficient, Induction- 85\% efficient).

$>$ The coil is safer as it stays cooler.

$>$ Higher efficiency is obtained i.e. lower electricity bills.

$>$ Output power remains constant.

> Shock hazards are absent in the cooking pan.

$>$ Temperature control is very flexible.

$>$ Cheaper in cost than readily available microwaveoven.

$>$ For cooking common kitchen-purpose steel utensils are sufficient.

\section{Disadvantages of Induction Cooking}

$>$ Expensive than a common electric hot plate.

$>\quad$ High resistivity and relative permeability heating vessels can only be used.

\section{RESONANT INVERTER}

The resonant converter consists of resonant L-C networks in which voltage and current waveforms vary sinusoidally during each switching period. The resonant circuit of a 
resonant converter contains a capacitor, an inductor, and resistance. When the power is connected, electrical energy is stored in the inductor and transferred to the capacitor. The amount of energy stored within the capacitor to be sent to the inductor. when the inductor and the capacitor exchange the energy, resonance will occur. The total amount of energy stored in the circuit remains unchanged during resonance. This total amount is equal to the amount of energy stored at the peak in the conductor or capacitor. As some energy is lost due to resistance within the resonance process, the entire amount of energy stored within the inductor decreases in each resonant exchange. The main reason for the development of Resonant inverters is the demand for energy-saving converter systems of high operating frequencies where switching of semi-conductor power components occurs at Zero voltage (ZVS) or zero current (ZCS) [6]. Different types of converter topologies exist for efficiently producing the time-varying magnetic field needed for induction heating.

The Resonant Converter is broadly classified into many types. Those are: -

$>$ Series Resonant inverter

$>$ Parallel Resonant inverter

$>$ Class E Resonant Converter

$>$ Class E Resonant Rectifier

$>$ Zero Voltage Switching (ZVS) Resonant Converter

$>$ Zero Current Switching (ZCS) Resonant Converter

$>$ Two Quadrant ZVS Resonant Converter

$>$ Resonant dc-link inverter

Quasi-Resonant Converter

All the modulation strategies commonly applied to control output power for achieving the desired power are based on modifying either switching frequency or duty cycle. The power converter topologies offer different performance characteristics with specific demands in terms of costs and hardware and control complexity. These systems are famous in literature as well as the design criteria for all their main parameters.

Class E resonant converter, also known as Class E amplifier, is one of the most used resonant converters in high-frequency power electronics and radiofrequency applications. It includes a single power switching device like MOSFET, two inductors, and two capacitors. It can perform both zero voltage switching and zero $\mathrm{dv} / \mathrm{dt}$ switching operation, which eliminates losses due to parasitic device capacitance. In this case, when the voltage crosses zero, the switching device turns on. Theoretically, it can eliminate the device turn-on loss if the switching is done at exactly the right time, and the efficiency of the converter can be very high.

\section{A. Class E Resonant Inverter}

Class E Resonant Inverter is a high-frequency inverter in which only one switching device is employed and produces nearly sinusoidal output for a DC input. The design of a Class E Resonant Inverter consists of a power switch $\mathrm{S}$, an L-C-R series resonant loaded circuit, a shunt capacitor $\mathrm{C}$ and an input inductor $\mathrm{L}_{\mathrm{d}}$. The switch device output capacitance and input inductor parasitic parallel capacitance are included in the shunt capacitor $\mathrm{C}$. In optimum operation, $\mathrm{L}_{\mathrm{d}}$ is a very large inductor providing a DC input current with ripples.
With a proper design, the converter can achieve zero-voltage switching and zero $\mathrm{dv} / \mathrm{dt}$ switching at turn-on transition. The power loss incurred in the circuit is very less due to ZVS and ZDS and by using a single switching device, switching losses are reduced. The output frequency is controlled by the pulse frequency given to the gate of MOSFET (or switching device) [7].

The basic circuit of class E inverter is shown in "Fig. 2.". To switch the resonant R-L-C circuit, the input driving signal $\mathrm{V}_{\mathrm{GS}}$ is fed to the power MOSFET which operates as a switch. A sinusoidal current will appear in the R-L-C circuit when the switching frequency of MOSFET matches with the resonance of the R-L-C circuit which is an enough loaded quality factor. At the same time, an oscillating voltage will appear on the drain-source end of MOSFET. The driving signal $\mathrm{V}_{\mathrm{GS}}$ is controlled accurately at the instants of drainsource voltage crossing zero to turn on the MOSFET, which is known as 'ZVS'.
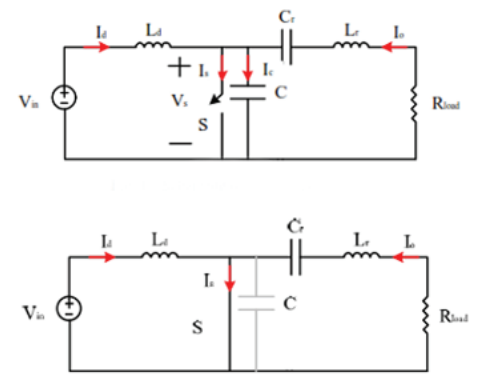

(a)

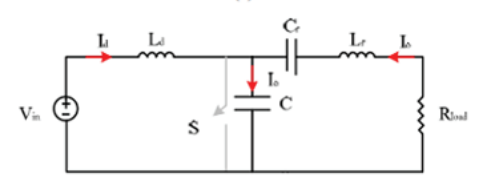

(b)

Figure 2. Class-E inverter operation states: (a) switch on; (b) switch off

The Schematic circuit of the class E inverter is shown in "Fig. 2." (a) when the switch $\mathrm{S}$ is on and (b) when the switch $\mathrm{S}$ is off. The circuit consists of two modes, the on mode while $\mathrm{V}_{\mathrm{GS}}$ is in the high state and the off mode while $\mathrm{V}_{\mathrm{GS}}$ is in the low state. When the MOSFET is turned on, the resonant circuit consists of $\mathrm{L}_{\mathrm{r}}, \mathrm{C}_{\mathrm{r}}$, and $\mathrm{R}_{\mathrm{L}}$ because the capacitance $\mathrm{C}$ is short-circuited by the switch, and the current conducts through the switch. The drain-source voltage becomes almost zero. When the MOSFET is turned off, the resonant circuit will consist of $\mathrm{C}, \mathrm{L}_{\mathrm{r}}, \mathrm{C}_{\mathrm{r}}$, and $\mathrm{R}_{\mathrm{L}}$ that are connected in series. The current flowing through capacitor $\mathrm{C}$ shapes the voltage across the switch. The drainsource voltage is amplified. The voltage across the switch device builds up slowly so that the switch has nearly zerovoltage turn-off. The voltage across the switch then increases, reaches its peak, and eventually drops down to zero, at which instant the switch is turned on. The zerovoltage turn-on is achieved at this moment. The inverter is switched at zero voltage VS across the switch. The circuit is turned on smoothly, current and voltage waveforms tend towards the state of steady operation over a time proportional to the value of inductance $L_{d}$. The increasing value of $\mathrm{L}_{d}$ extends the start-up time, decreasing the value of 
$\mathrm{L}_{\mathrm{d}}$ raises pulsation of the source current id of the inverter. A constant value of the inverter's supply current $i_{d}$ during its steady operation is produced by higher inductance $\mathrm{L}_{d}$. when the switch turns on, the energy stored in the shunt capacitance $\mathrm{C}$ is zero, yielding zero turn-on switching loss.

In the state of conducting, Switch with resistance $R_{T}\left(R_{T}\right.$ $<<\mathrm{R}_{\mathrm{L}}$ ) short-circuits capacitance $\mathrm{C}$. The series resonant circuit consists of inductance $\mathrm{L}_{\mathrm{r}}$, capacitance $\mathrm{C}_{\mathrm{r}}$, load resistance $R_{L}$ and switch resistance $R_{T}$. Pulsation of $\omega_{01}$ of the resonant circuit $\mathrm{R}_{\mathrm{L}}, \mathrm{R}_{\mathrm{T}}, \mathrm{L}_{\mathrm{r}}, \mathrm{C}_{\mathrm{r}}$ is

$$
\omega_{01}=\sqrt{\frac{1}{L_{r} C_{r}}-\left(\frac{R_{L}+R_{T}}{2 L_{r}}\right)^{2}}
$$

And qualityfactor $\mathrm{Q}_{01}$ of resonantcircuit $\mathrm{R}_{\mathrm{L}}, \mathrm{R}_{\mathrm{T}}, \mathrm{Lr}, \mathrm{Cr}$ is:

$$
\mathrm{Q}_{01}=\frac{\omega_{0} L_{r}}{\left(R_{L}+R_{T}\right)}=\frac{1}{\omega_{0} C_{r}\left(R_{L}+R_{T}\right)}
$$

When the switch is off, the series resonant circuit comprises inductance $\mathrm{Lr}$, capacitances $\mathrm{C}$ and $\mathrm{Cr}$, and load resistance $\mathrm{RL}[8-9]$. The capacitances $\mathrm{C}$ and $\mathrm{Cr}$ are in series, and the equivalent capacitance $\mathrm{C}_{Z}$ is lower than $\mathrm{C}$ and $\mathrm{C}$ and equals:

$$
\mathrm{C}_{\mathrm{Z}}=\frac{C C_{r}}{C+C_{r}}
$$

$\omega_{02}$ of the resonant circuit $\mathrm{R}_{\mathrm{L}}, \mathrm{C}, \mathrm{Lr}, \mathrm{Cr}$ is

$$
\omega_{02}=\sqrt{\frac{1}{\frac{L_{r} c_{r} c}{c_{r}+c}}-\left(\frac{R_{L}}{2 L_{r}}\right)^{2}}
$$

and the quality factor $\mathrm{Q}_{02}$ of theresonant circuit $\mathrm{R}_{\mathrm{L}}, \mathrm{C}, \mathrm{Lr}, \mathrm{Cr}$ is:

$$
\mathrm{Q}_{02}=\frac{\omega_{02} L_{r}}{\left(R_{L}\right)}=\frac{1}{\frac{\omega_{02} R_{L} C_{r} C}{c_{r}+c}}
$$

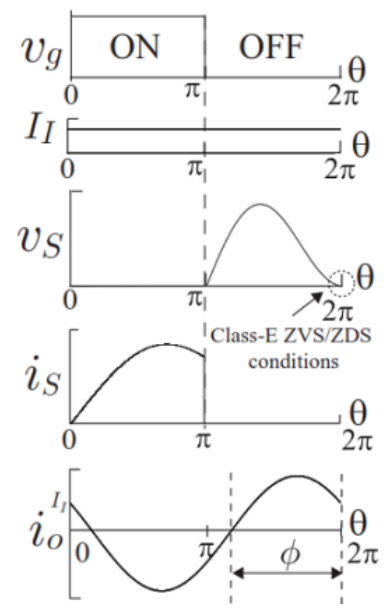

Figure 3. Waveforms of class-E inverter

The class-E inverter achieves high-power conversion efficiency at high frequencies because it satisfies the (ZVS/ZDS) conditions simultaneously at the switch turn-on instant [10-11]. Switching loss is minimized because of the ZVS and jump-less currents at turn-on instant. The class-E ZVS/ZDS conditions are expressed as

$$
\begin{aligned}
& \mathrm{V}_{\mathrm{S}}(\mathrm{T})=0 \\
& {\frac{d v_{S}}{d t}}_{t=T}=0
\end{aligned}
$$

where $\mathrm{T}$ is the period of input voltage source $\mathrm{V}_{\text {in }}$. The conditions "(7)" and "(8)" are called (ZVS) and (ZDS) conditions [12].

The parameters of the circuit at optimum operation are as are listed in equations 9 to 14

The full load resistance is:

$$
\mathrm{R}_{\mathrm{L}}=\frac{8 V_{\text {in }}^{2}}{\left(\pi^{2}+4\right) P}
$$

where $P$ is the output power. The component values for the load network are

$$
\begin{aligned}
\mathrm{C} & =\frac{I_{0}}{\omega \pi V_{i n}^{2}}=\frac{1}{\omega \pi R_{L}\left(\frac{\pi^{2}}{4}+1\right) \frac{\pi}{2}}=\frac{2.165}{R_{L} \omega} \\
\mathrm{C}_{\mathrm{r}} & =\frac{1}{\omega R_{L}\left(Q-\frac{\pi\left(\pi^{2}-4\right)}{16}\right)}=\frac{1}{\omega_{s}(Q R-0.3533 R)} \\
\mathrm{L} & =\frac{Q R_{L}}{\omega}
\end{aligned}
$$

and the choke inductor is

$$
\mathrm{L}_{\mathrm{d}}=2\left(\frac{\pi^{2}}{4}+1\right) \frac{R_{L}}{f}=0.4001 \frac{R_{L}}{\omega}
$$

The Resonant frequency is

$$
\mathrm{f}_{\mathrm{o}}=\frac{1}{2 \pi \sqrt{L_{r} C_{r}}}
$$

\section{B. Soft-Switching Technology}

Soft-Switching is defined as higher energy conversion efficiency at high switching frequencies that can be obtained by manipulating the voltage or current now of switching to become zero. Soft switching can be classified into two types, ZVS turn-on, and ZCS turn-off. Soft switching is very important in induction cooking applications. The cooking pan's surface resistance is increased by increasing the switching frequency and be able to transfer the output power into the cooking pan. If the switching frequency is pushed higher, then the switching loss will always transfer in the form of heat and excessive heat may damage the power switch and make the device reliability a major issue.

when the switching frequency increases, high-frequency noise, and switching losses increase because semiconductor devices are not entirely ideal. If the device switching is forced while there is still energy stored inside the device, such as the minority carrier charge stored in the base region of Bipolar Junction Transistor (BJT) or the accumulated charge stored in the output capacitor of MOSFET, the energy must be converted into heat and other forms of electromagnetic energy and can cause switching losses if the energy has nowhere to travel. Then soft switching technology solves the problem. The energy stored inside the device is transferred to other storage devices such as inductors and capacitors before the switching action takes 
place by LC resonance, auxiliary switches, or other methods is the main principle of soft switching.

\section{SOLAR -BASED INDUCTION COOKER}

\section{A. Solar Power}

Solar energy is a good and clean source of energy, which may help the world in experiencing the dirty and short of non-renewable resources, such as coal, etc. Recently the solar power generation systems are getting more conscious because solar energy is largely available, more efficient, and more environmentally friendly as compared to conventional power generation systems such as fossil fuel, coal, or nuclear. The Photo Voltaic (PV) system that uses solar power to produce electricity is considered as one of the renewable energies has great potential when compared to the traditional energy resources and developing increasingly fast compared to its equivalent of renewable energies. The main advantage of PV technology is that it does not have any moving parts. Therefore, the PV system is extremely robust, it has a long lifetime and low maintenance demand. It is one of the best solutions that offer environmentally friendly power generation [13].

The PV systems as an electrical generator still has problems related to the generator conversion efficiency and its output power. Especially under low radiation states, the efficiency of electric power generation is very low. PV generation relies on weather conditions. The amount of electric power generated by solar arrays depends upon a variety of conditions like solar irradiance, temperature, and angle of the incident light. When the maximum power is not achieved then the effectiveness of the PV system decreases. Therefore, there is a need for the control design to tracking a Maximum Power Point (MPP) by considering the environmental changes. The MPPT (maximum power point tracking) Control technique plays an important role in the PV systems by tracking the continuously varying maximum power point of the solar array. The primary task of a maximum power point tracking (MPPT) network in a PV system is to continuously tune the system so that maximum power is drawn from the solar panels nevertheless of weather or road conditions.

\section{B. MPPT Algorithms}

MPPT Algorithms are classified as:

1) Hill-climbing techniques

- Perturbation and observation (P\&O) methods.

- Incremental conductance methods.

2) Fuzzy logic

3) Neural Network

4) Fractional open circuit voltage

5) Fractional short circuit current

There are several MPPT control schemes from conventional algorithms such as $\mathrm{P} \& \mathrm{O}$ and Incremental Conductance or implement Artificial Intelligence. Due to simplicity and ease of implementation, Perturb and Observe (P\&O) is the most used algorithm in MPPT. The main advantage of the MPPT control algorithm, both conventional and intelligent algorithms is having the ability to provide maximum energy to be transferred to the load. Usually, MPPT can be operated by connecting a power converter between the PV system and load. By adjusting the power converter's duty cycle, maximum power can be achieved by MPPT. The internal resistance in PV and load resistance is compared by the duty cycle. Among all the methods, the $\mathrm{P} \& \mathrm{O}$ method has drawn much attention due to its simplicity [14].

The intermittency issue is solved as this cooking system is designed by the Class E resonant topology and with the Perturb \& Observe algorithm which is used for the MPPT to increases the reliability of this cooking system. When this cooking system is incorporated at a larger scale it would probably aid them in leading a sustainable lifestyle and reduce the environmental impacts produced by the conventional system. A Solar powered induction-based cooking system was proposed, in a bid to replace this conventional methodology.

"Fig. 4." shows the schematic circuit of solar induction cooking. Solar energy is the primary source of input to the solar-based induction heating system. Solar energy coming from the sun is the primary input to the system. Using an inverter, the solar power received by the array of a photovoltaic cell is further converted into electric energy. This solar induction cooker makes use of a solar panel, which gives a variable dc output. Using an inverter circuit, the $\mathrm{dc}$ is converted into ac voltage and fed into the induction cooking circuit. By using a rectifier $\mathrm{AC}$ voltage is then converted to DC. Pulsating DC from rectifier output is removed with the help of a filter. The DC voltage and pulses for triggering of MOSFET are supplied to the class E Resonant inverter. For generating the AC voltage, MOSFET is used as a switching device. The pulse width modulated signal given to the gate of MOSFET controls the temperature of the generated heat. Therefore, an eddy current in the pan will be induced by placing a cooking pan close to the induction coil. Heat energy will be produced on the surface of the pan because of this. The heat dissipation occurs due to the internal resistance of the pan. Thus, it is the pan itself that is heated up and not the heater that heats and cooks the food [15].

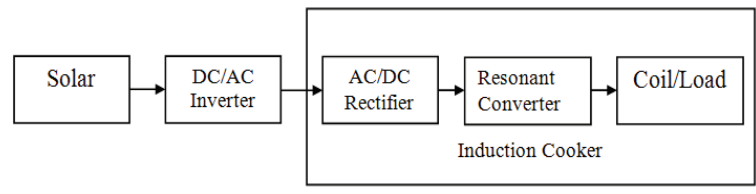

Figure 4. Schematic circuit of solar induction cooking

\section{Design And Simulation Of Solar-Based INDUCTION HEATING SYSTEM}

The objective of this project is to simulate a solar-based induction heating system incorporating a class $\mathrm{E}$ resonant inverter. Simulation of conventional induction cooker circuit and solar energy-based induction cooker circuit using class $\mathrm{E}$ resonant inverter is done in MATLAB. 


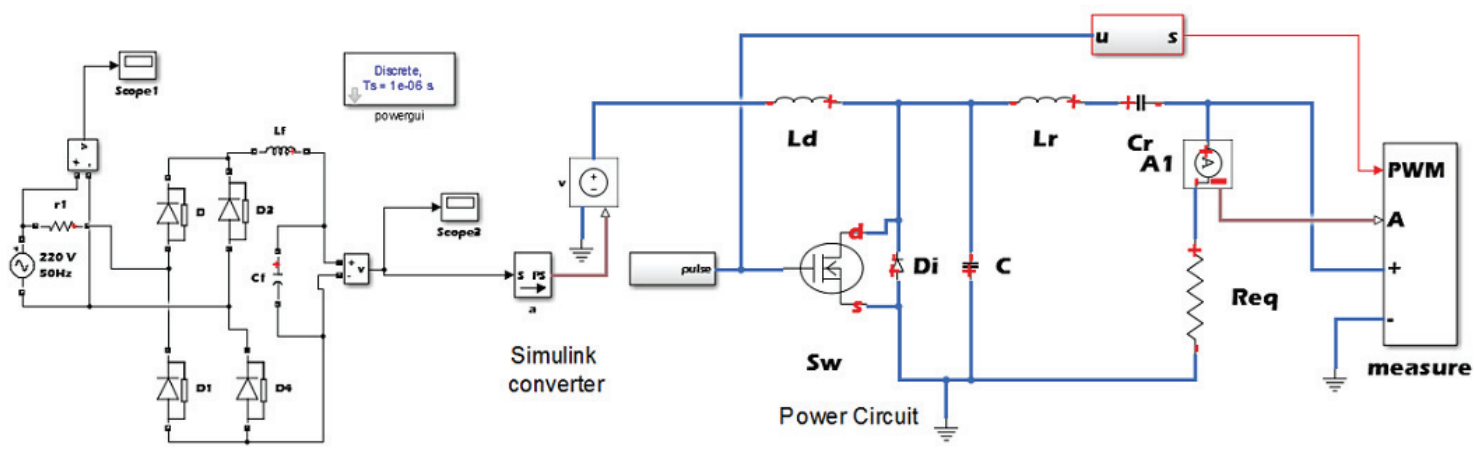

Adaptor Circuit

Figure 5. Conventional adaptor-based induction heating system with resonant E converter

Induction heating is a popular technique for producing very high heat in a fraction of time. Induction cooking is one of the applications of induction heating that is employed for residential and commercial usage. High power factor and low line current are achieved with the help of class $\mathrm{E}$ resonant inverter, which is very interesting in terms of commercial production. With a very high rate of change within the magnetic field, a high-frequency AC flowing through the coil provides the proper heat which is useful for cooking.

To increase the frequency and for the wiring protection, induction cook tops consist of electronic devices. The frequency at the coil is very large than the input frequency (generally, more than 1000 times). Induction cookware is generally made up of ferrous metals because these are relatively poor conductors of electricity, so they have high resistance. When a current is passed through a high resistive material, much of the current is converted into heat energy. The heat energy which is used to cook food on an induction cook top comes from this electrical resistance and changes in the magnetic field of the cookware.

\section{A. Simulation of Conventional Induction Heating System}

' Fig. 5,' shows the main Circuit with a conventional adaptor-based induction heating system with Class E Resonant Converter. The circuit consists of 4 parts: rectifier, filter, high-frequency inverter, and resonant load. The rectifier module is a full-bridge rectifier (D1, D2, D3, D4). The second portion of the system is a capacitive filter $\left(\mathrm{L}_{\mathrm{f}}\right.$, $\mathrm{C}_{\mathrm{f}}$ ). The ripple components are minimized by this filter. The third is a high-frequency converter (Class E Resonant Inverter) to convert the constant $\mathrm{DC}$ to high-frequency $\mathrm{AC}$ by switching the MOSFET which is used as a power source and can be driven by the pulse signals. PWM generator is used for pulse generation. High-frequency alternating current is generated in the Resonant Load $\left(\mathrm{L}_{\mathrm{r}}, \mathrm{C}_{\mathrm{r}}, \mathrm{R}_{\mathrm{L}}\right)$. The parameters used for the filtering side and the resonant converter are given in below table II.
TABLE II.

PARAMETERS

\begin{tabular}{|c|c|c|}
\hline $\begin{array}{c}\text { Parameter } \\
\text { Expanded }\end{array}$ & Symbol & $\begin{array}{c}\text { Value of the } \\
\text { parameter }\end{array}$ \\
\hline Input Voltage & $\mathrm{V}$ & $220 \mathrm{~V}$ \\
\hline Filter Inductor & $\mathrm{Lf}$ & $500 \mu \mathrm{H}$ \\
\hline $\begin{array}{c}\text { Filter } \\
\text { Capacitance }\end{array}$ & $\mathrm{Cf}$ & $4.7 \mu \mathrm{F}$ \\
\hline Choke Inductor & $\mathrm{Ld}$ & $31.83 \mu \mathrm{H}$ \\
\hline $\begin{array}{c}\text { Shunt } \\
\text { Capacitor }\end{array}$ & $\mathrm{C}$ & $1.7229 \mu \mathrm{F}$ \\
\hline $\begin{array}{c}\text { Resonant } \\
\text { Inductor }\end{array}$ & $\mathrm{Lr}$ & $517.042 \mu \mathrm{H}$ \\
\hline $\begin{array}{c}\text { Resonant } \\
\text { Capacitance }\end{array}$ & $\mathrm{Cr}$ & $0.10 \mu \mathrm{F}$ \\
\hline Resistance & $\mathrm{Req}$ & $10 \Omega$ \\
\hline
\end{tabular}

AC supply of $220 \mathrm{~V}$ is applied as input to the circuit. During the positive half cycle, the diodes D1, D4 operate. Mode 1 is active when the switch is ON. PWM pulses generation for the class $\mathrm{E}$ converter with a duty cycle of $50 \%$ is shown in "Fig. 6". During mode 1, the active switch is turned $\mathrm{ON}$ with ZVS, the current flows through $\mathrm{L}_{\mathrm{d}}$. The resonant circuit consists of $\mathrm{L}_{\mathrm{r}}, \mathrm{C}_{\mathrm{r}}$, and $\mathrm{R}_{\mathrm{L}}$ because the capacitance $\mathrm{C}$ is short-circuited by the switch, and the current conducts through the switch. The drain-source voltage becomes almost zero. The current through the switch increases till the switch gets off. During the negative half-cycle, the diodes D2 and D3 of the bridge rectifier will operate. Mode 2 is activated when $\mathrm{Q}$ is turned OFF. The resonant circuit will consist of $\mathrm{C}, \mathrm{L}_{\mathrm{r}}, \mathrm{C}_{\mathrm{r}}$, and $\mathrm{R}_{\mathrm{L}}$ that are connected in series. The current flowing through capacitor $\mathrm{C}$ shapes the voltage across the switch. The drain-source voltage is amplified. The voltage across the switch device builds up slowly so that the switch has nearly zero-voltage turn-off. The voltage across the switch then increases, reaches its peak, and eventually drops down to zero, at which instant the switch is turned on. 


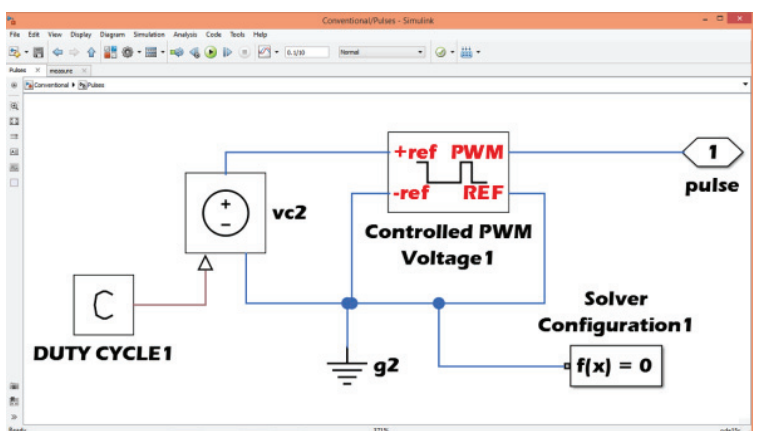

Figure 6. PWM pulses generation for the class E converter

Based on the desired power and load characteristics, the duty cycle can be adjusted whereas the operating frequency is fixed. Due to different frequencies that cause lowfrequency interferences amplified by the iron, the fixedfrequency control has more advantages than different operating frequencies such as reducing the electromagnetic noise spectrum and avoiding the acoustic noise. The measurements of voltage, current, and power along with the PWM generated pulses are taken from the measurements sub-system block shown in "Fig. 7".

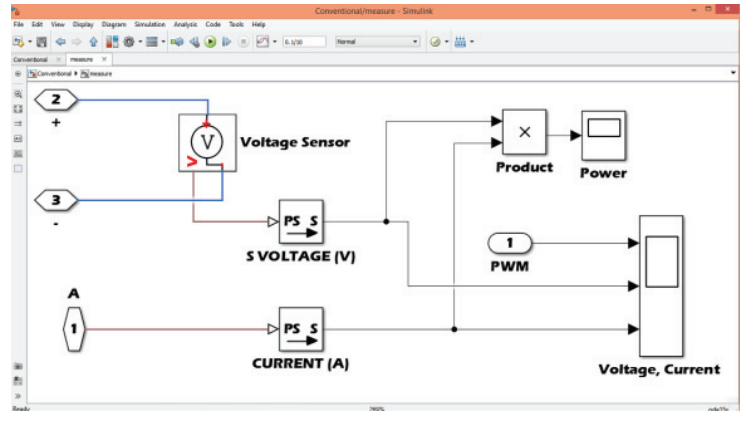

Figure 7. Measurements subsystem block

"Fig. 8," shows the Driver pulses, Output voltage, and current at $20 \mathrm{kHz}$ frequency. "Fig. 9," the power developed at $20 \mathrm{kHz}$ frequency. The average power developed is around $2000 \mathrm{~W}$ which is sufficient for the cooking application.
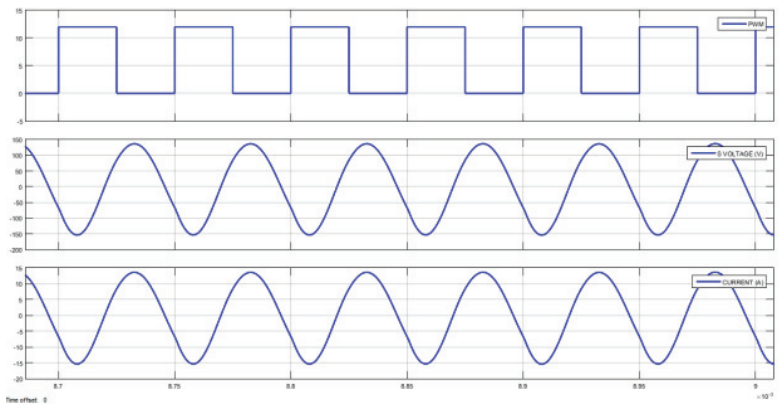

Figure 8. Driver pulses, Output voltage(V), and current(A) at $20 \mathrm{kHz}$ frequency

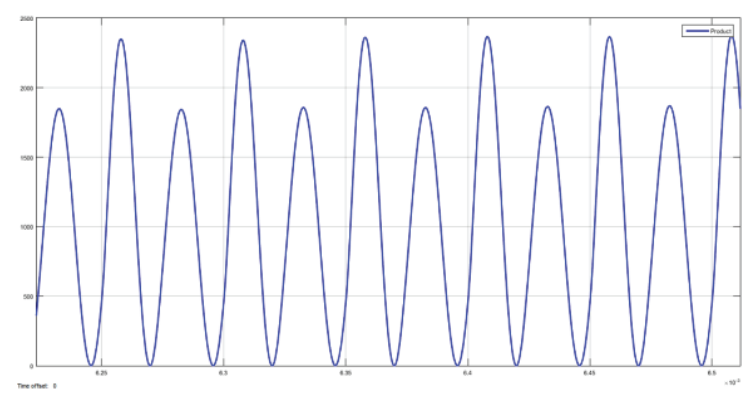

Figure 9. Power developed (W) at $20 \mathrm{kHz}$ frequency

\section{B. Simulation of Solar-Based Induction Heating System}

"Fig. 10," shows the Main Circuit with a solar-based induction heating system with resonant $\mathrm{E}$ converter. The solar PV array is taken to simulate the solar power in which MPPT is achieved using the $\mathrm{P} \& \mathrm{O}$ algorithm. The variable DC from the PV array is converted into constant DC by the MPPT algorithm and then converted into $\mathrm{AC}$ by the inverter. The AC output is converted to DC voltage by the Rectifier and then with the help of Class E Resonant Inverter the output is obtained. The load is represented with an equivalent resistance the same as the conventional system.

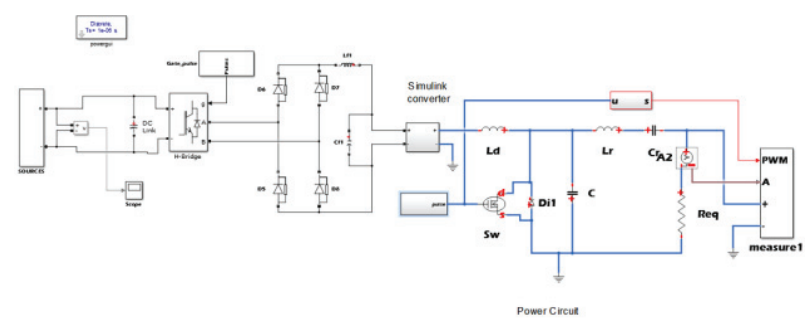

Figure 10. Solar-based induction heating system with resonant E converter

"Fig. 11," shows the solar PV implementation in MATLAB with irradiance and temperature. For regulating AC power output, the MPPT algorithm implementation is shown in "Fig. 12."

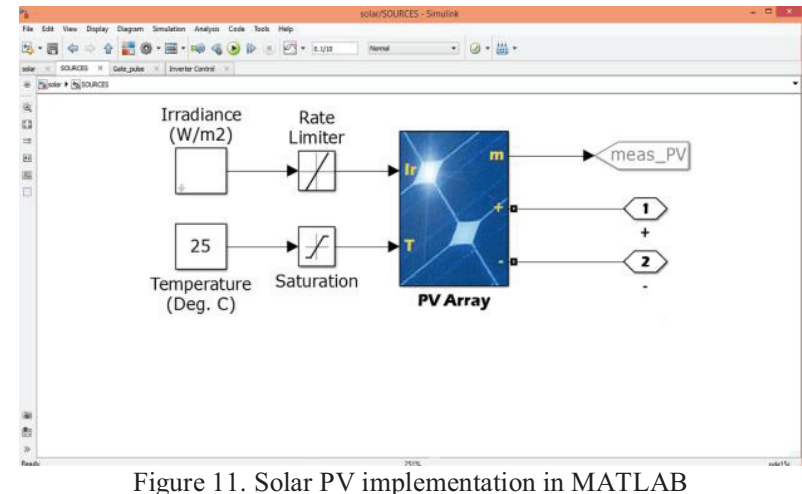




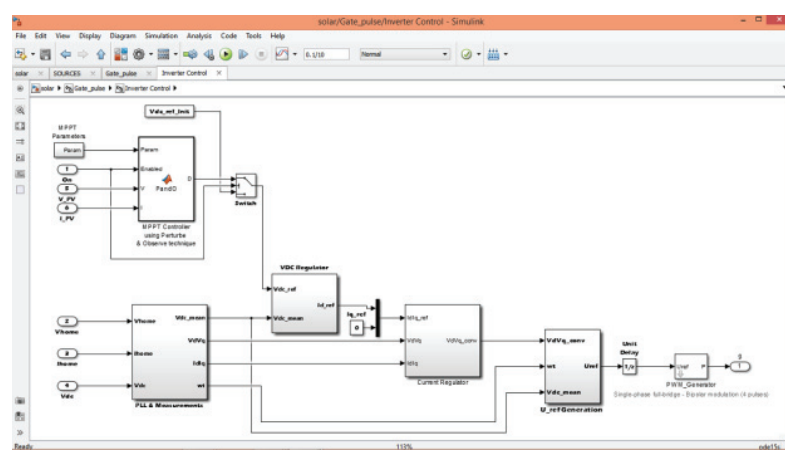

Figure 12. MPPT Algorithm Implementation

"Fig. 13," shows the Driver pulses, Output voltage, and current at $20 \mathrm{kHz}$ frequency. "Fig. 14," shows the power developed at $20 \mathrm{kHz}$ frequency. The average power is around $2000 \mathrm{~W}$ sufficient for the cooking application.

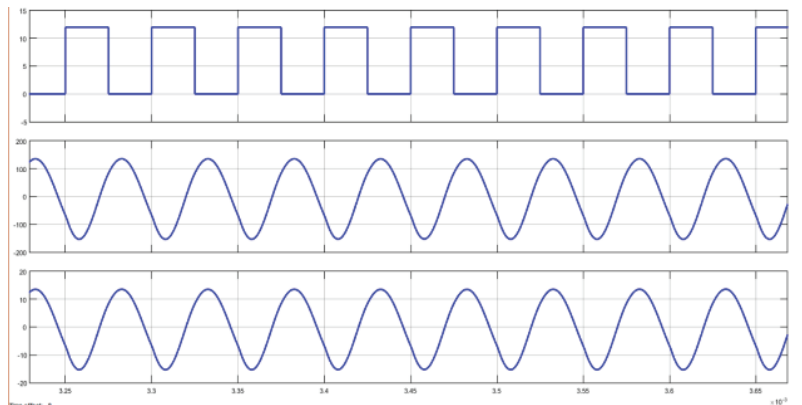

Figure 13. Driver pulses, Output voltage, and current at $20 \mathrm{kHz}$ frequency

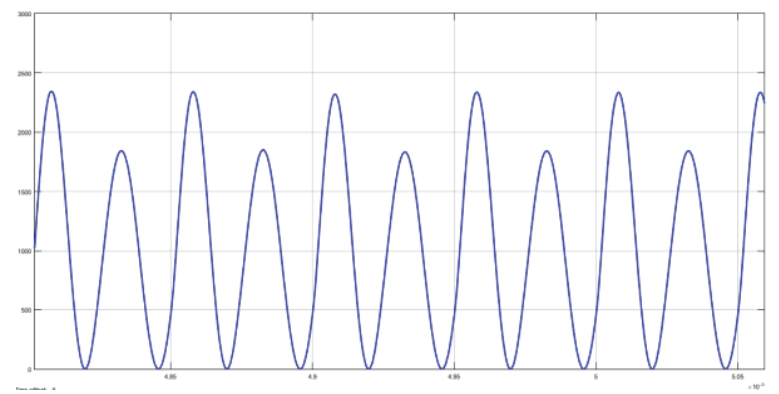

Figure 14. Power developed (W) at $20 \mathrm{kHz}$ frequency

\section{Conclusions}

Induction heating technology is a very attractive technology that is becoming very fascinating due to the high conversion efficiency for cooking applications. Induction heating technology not only provides the advantage of having a better efficiency conversion compared to the other traditional technologies but also provides compact size, safety, high reliability, cleanliness, low running cost, and non-acoustic noise. The combination of solar energy and induction heating technique is an efficient solution for the cooking application. In an induction cooking system, heat is generated by electricity. In a solar induction cooking system, solar energy is used as a source of power to generate electricity by which heat is generated. MOSFETs instead of IGBTs are used to achieve higher frequencies and lower costs. For efficient conversion, resonant conversion is used. Due to high efficiency and high-power density, resonant converters consisting of soft switching are generally preferred in domestic induction heating applications. An effective control scheme of class $\mathrm{E}$ resonant converter in induction heating by using solar energy is presented. The simulation models are done in MATLAB-SIMULINK. The maximum output power will be around $2000 \mathrm{~W}$ and the resonant frequency is $20 \mathrm{kHz}$. Low switching losses, increased efficiency, increased bandwidth, better power transfer are the advantages of class E resonant converter.

This new system may provide a valuable reference to decide on environmental control strategies because solar induction heating is a pollution-free, clean, safe heating technique.

\section{REFERENCES}

[1] Bikal Adhikari, Jagan Nath Shrestha, Shree Raj Shakya, "Design and Simulation of a Solar Electricity Based Induction Cooker using Quasi Resonant Topology," Proceedings of IOE Graduate Conference, pp. 1-11, 2016.

[2] Farheen Naaz Ansari, Dr. K Subramanian," Solar PV Based Resonant Inverter For Induction Cooker," International Conference on Trends in Electronics and Informatics (ICEI), pp. 888-891, 2017.

[3] A. Vijin Prabhu, P. Jeba, R. Babu, P. S. Samuel Ratna Kumar, "A Review on Solar Based Induction Cooker using Different Topologies," International Journal of Scientific Research and Review, Volume 7, Issue 10, 2018.

[4] M. E. Tulu, D. Yildirim, " Induction Cooker Design with Quasi Resonant Topology using Jitter Drive Method," IEEE 12th conference on Environment and EE (EEEIC), pp 1-6, May 2013.

[5] Bikal Adhikari, Jagan Nath Shrestha, Shree Raj Shakya, "A New Approach to the design of DC Powered Induction Cooker," Kathford Journal of Engineering and Management, Volume 1, Issue 1, Nov 2018.

[6] V. V. Kulkarni, L. B. Swami, "MOSFET Based High Frequency Inverter for Induction Heating Equipment using MATLAB/SIMULINK Environment," International Journal of Innovations in Engineering Research and Technology [Ijiert], Volume 1, Issue 1, Nov 2014.

[7] K. Peng and E. Santi, "Class E Resonant Inverter Optimized Design foe High Frequency $(\mathrm{MHz})$ Operation using eGaN HEMTs," Applied Power Electronics Conference and Exposition (APEC), Charlotte, NC, pp. 2469-2473, 2015.

[8] Mungikar, Hemlata N., and V. S. Jape. "Induction cooking application based on Class E resonant inverter: Simulation using MATLAB." International Journal of Science and Research " pp 1874-1877, 2015

[9] Bugade, Vilas, Hemlata Joshi, and Ekta Mishra. "Modeling and Simulation of Class E Resonant Inverter for Induction Cooking Application."

[10] Lucia, Oscar, Jose M. Burdio, Ignacio Millan, Jesus Acero, and Luis A. Barragan. "Efficiency-oriented design of ZVS half-bridge series resonant inverter with variable frequency duty cycle control." IEEE Transactions on Power Electronics 25, no. 7 pp 1671-1674, 2010

[11] Kumar, P. Sharath, N. Vishwanathan, and Bhagwan K. Murthy. "A full bridge resonant inverter with multiple loads for induction cooking application." In 2013 International Conference on Energy Efficient Technologies for Sustainability, pp. 119-124. IEEE, 2013.

[12] Yusop, S. Saat, S. K. Nguang, H. Husin, Z. Ghani, "Design of Capacitive Power Transfer using a Class E Resonant Inverter," Journal of Power Electronics, Volume 16, no. 5, pp. 1678-1688, Sep 2016. 
[13] Bandile I. Sibiya, Dr. Chitra Venugopal, "Solar Powered Induction Cooking System," 1st International Conference on Power Engineering, Computing and Control, PECCON-2017, 24 March 2017.

[14] A. C. Subrata, T. Sutikno, S. Padmanaban, and H. S. Purnama, "Maximum Power Point Tracking in PV Arrays with High Gain DC-DC Boost Converter," 6th International
Conference on Electrical Engineering, Computer Science and Informatics (EECSI), pp. 358-362, 2019.

[15] Vilas Bugade, Hemlata Joshi, Ekta Mishra, "Modeling and Simulation of Class E Resonant Inverter for Induction Cooking Application," International Journal of Engineering Trends and Technology (IJETT), Volume 60, Issue 1, June 2018 . 